Harris-Smith, P. W., Smith, H. \& Keppie, J. (1958). J. gen. Microbiol. 19, 91-103

\title{
Production in vitro of the Toxin of Bacillus anthracis Previously Recognized in vivo
}

\author{
By PATRICIA W. HARRIS-SMITH, H. SMITH AND J. KEPPIE \\ Microbiological Research Establishment, Porton, Wiltshire
}

\begin{abstract}
SUMMARY: A lethal oedema-producing toxin has been made in vitro in serum cultures of Bacillus anthracis which is identical with the toxin originally recognized in vivo. Toxin is produced by the attenuated immunogenic Sterne strain as well as by the virulent N.P. strain. Previous non-recognition of the toxin in cultures was due to its early appearance and rapid disappearance under ordinary growth conditions. A toxin-destroying mechanism was demonstrable in organisms from cultures grown for more than a few hours. Attempts to maintain the toxin concentration or to increase it by addition of various nutrilites to batch culture failed; only by continuous culture have the organisms been kept in their toxigenic growth phase. Traces of the toxin appear in cultures in tryptic meat broth; these are increased by the addition of large molecular constituents of serum which appear to play an important role in toxin production.
\end{abstract}

Until recently the product of Bacillus anthracis which is responsible for death in anthrax was unknown. No lethal endo- or exotoxin had been found in cultures of the organism in vitro (Eurich \& Hewlett, 1930; Sobernheim, 1931; King \& Stein, 1950). As a result of working with organisms grown in vivo rather than with those from artificial culture, Smith, Keppie \& Stanley (1955) showed that $B$. anthracis does form a specific lethal oedema-producing exotoxin. It was found in the plasma of guinea-pigs dying of anthrax. Although the characteristics of the toxin were clearly established it was not demonstrated in cultures in vitro until some time had elapsed. The failures to detect the toxin under these conditions was due to its exceptionally early appearance followed by its rapid disappearance, which meant that toxin was only detectable during a very short period, at an unusually early stage of the culture. The present paper describes the production of the toxin in vitro, also its properties and attempts to improve its yield and to prolong its activity under various culture conditions.

\section{METHODS}

Organisms used. The virulent N.P. strain of Bacillus anthracis and the attenuated Sterne and H.M. strains were used.

Guinea pig blood and serum. Blood was removed from guinea pigs by cardiac puncture and collected into heparin (10 i.u./ml.) or immediately defibrinated, under as aseptic conditions as possible. After removing the blood cells, the plasma contained a small amount of haemoglobin and was used for toxin production within 2 days of its collection.

Anthrax toxin produced in guinea pigs. This was obtained as described by Smith et al. (1955). 
Albumin I (Armour). This was Fraction $\mathrm{V}$ of bovine plasma prepared by the Cohn \& Edsall separation. It was not especially purified and formed a brown solution.

Albumin II. This was a special sample of bovine albumin which showed no evidence of heterogeneity when examined electrophoretically or in the ultracentrifuge.

$\gamma$-Globulin. This was Fraction II of bovine plasma prepared by the Cohn \& Edsall separation, and supplied by L. Light and Co.

Guinea-pig haemoglobin. Well washed guinea-pig red blood corpuscles were haemolysed with distilled water; after centrifugation the solution was freeze dried.

Bovine and sheep haemoglobin. Prepared as described for guinea-pig haemoglobin.

Estimation of bacterial growth. The number of bacterial chains $(2-8$ bacilli) $/ \mathrm{ml}$. of culture was obtained from the average number of chains/microscope field of a standard film (Keppie, Smith \& Harris-Smith, 1955); 1 chain/field was equivalent to $1.5 \times 10^{7}$ chains $/ \mathrm{ml}$. $( \pm 50 \%)$. In media consisting of mainly tryptic meat digest, Bacillus anthracis grew in longer chains than in plasma. For this reason an estimate of bacterial growth was obtained from the extinction of light by the turbid solutions, measured in an EEL spectrophotometer. Appropriate blanks were used in these estimations, and in Table 6 the readings of the EEL spectrophotometer are quoted as measures of bacterial growth.

Assay of toxin in culture filtrates. The skin test for oedema production described by Smith et al. (1955) was used for routine assay of samples of culture which had been filtered sterile through Millipore membranes. The average result of duplicate assays are recorded here in the manner described by these authors, i.e. 8:40 indicates a lesion of skin-fold thickness $8 \mathrm{~mm}$. and diameter $40 \mathrm{~mm}$. Tests for lethality in mice and guinea pigs were carried out as described by Smith et al. (1955).

\section{RESULTS}

Production of toxin from the virulent N.P. strain of Bacillus anthracis

The initial experiments were related to the fact that toxin appeared in the blood of guinea pigs dying of anthrax when the bacterial count was $c .1 \times 10^{7}$ chains $/ \mathrm{ml}$. and the animal was $c .7 \mathrm{hr}$. from death (Smith et al. 1955). In preliminary experiments, heparinized or defibrinated guinea-pig blood (9 ml.) was inoculated with a suspension ( $1 \mathrm{ml} ., 3 \times 10^{8}$ spores) of Bacillus anthracis strain N.P. spores in tryptic meat digest, which had been incubated at $37^{\circ}$ for $30 \mathrm{~min}$. to germinate the spores. The mixtures were shaken at $37^{\circ}$ in a Warburg bath at 120 strokes/min. with air containing $20 \%(\mathrm{v} / \mathrm{v}) \mathrm{CO}_{2}$ continuously passing over them. Samples tested by the skin-assay showed that the toxin concentration was maximal at $4 \mathrm{hr}$. (size of skin lesion $8: 35-10: 40$ ) and had disappeared by 7-8 hr. after the start of inoculation.

Further experiments soon established that serum could be used as effectively as whole blood; also that the maximum concentration of toxin and its subsequent rapid disappearance were not greatly affected by varying the following: 
conditions of cultivation: the presence or absence of heparin; rate of shaking or aeration; temperatures of $28^{\circ}, 34^{\circ}$ or $37^{\circ}$; different batches of guinea-pig blood or serum. In all cases, as soon as a certain amount of growth had occurred (count c. 5-10 $\times 10^{7}$ fully developed chains $/ \mathrm{ml}$.) the toxin concentration was maximal and then rapidly disappeared (at counts greater than 1-2 $\times 10^{8}$ chains $/ \mathrm{ml}$.). The size of the initial inoculum was somewhat critical if a high maximal concentration of toxin was to be obtained. The results in the upper part of Table 1 show that an inoculum size lower than the optimal resulted in a slightly less rapid appearance and disappearance of the toxin, but the maximal toxin concentration was not as high as that obtained with the optimal size of inoculum. A large inoculum resulted in a very rapid appearance and disappearance of the toxin. The optimal inoculum size and the conditions of culture described in Table 1 were used for the production of toxin for all subsequent work.

\section{Production of toxin by the virulent non-capsulated immunogenic Sterne strain of Bacillus anthracis}

The data in the lower part of Table 1 show that toxin was produced by the Sterne strain of Bacillus anthracis. The pattern of early appearance and rapid disappearance of toxin and the existence of an optimal inoculum size for maximal toxin production was the same as for the virulent strain. The capsulated attenuated H.M. strain of $B$. anthracis did not produce demonstrable toxin when tested under the conditions in Table 1.

Toxin concentrations similar to those quoted in Table 1 were obtained when the N.P. or the Sterne strains were grown for short periods in human, calf or sheep serum under the conditions described in Table 1.

A comparison of the properties of the anthrax toxin prepared in vitro and in vivo

The toxins formed in vitro by the N.P. and Sterne strains of Bacillus anthracis were compared with that produced by the N.P. strain in vivo. The results shown in Table 1 demonstrate the difficulty of obtaining cultures at the peak of toxin production. For the following tests, cultures were taken at 15-30 min. intervals between 3.5 and $4.5 \mathrm{hr}$. after the start of incubation. Only in this way could toxin be obtained which approached in potency that invariably present in the plasma of guinea pigs dying of anthrax. When, in addition to the optimal conditions outlined in Table 1, cultures were grown in an atmosphere of $20 \%(\mathrm{v} / \mathrm{v}) \mathrm{CO}_{2}$ in air, the filtrates contained on the average slightly more toxin than those grown in air without added $\mathrm{CO}_{2}$. The use of $\mathrm{CO}_{2}$ appeared to some extent to broaden duration of the toxin peak, thus making it easier to obtain samples of maximum toxicity. Carbon dioxide + air was used whenever filtrates of maximum toxicity were required. On average, the Sterne strain of $B$. anthracis produced slightly higher concentrations of toxin than did the N.P. strain.

Oedema production. In the standard skin test for oedema production lesions of 7-10:35-40 were obtained after injecting toxic filtrates from N.P. and 
Sterne strains of Bacillus anthracis. The lesions formed by toxin produced in vivo were 8-10:40-45. The null point (Smith et al. 1956) of the toxin prepared in vivo was at a dilution of $1 / 256$; the corresponding dilutions for toxic filtrates from the Sterne and N.P. strains were $1 / 256$ and 1/128, respectively.

Lethality to mice and guinea pigs. Results of lethality tests on toxic filtrates from subcultures of N.P. and Sterne strains of Bacillus anthracis are shown in Table 2.

Table 2. The lethality of Bacillus anthracis toxic filtrates for mice and guinea pigs and its specific neutralization

Antiserum (i) was prepared by hyperimmunizing horses with living avirulent B. anthracis spores; $1 / 5$ of volume of toxic filtrate was added.

Antiserum (ii) was prepared by hyperimmunizing horses with the immunizing antigen of Belton \& Strange (1954); $1 / 5$ of volume of toxic filtrate was added.

Toxic filtrates came from cultures in air containing $20 \%(\mathrm{v} / \mathrm{v}) \mathrm{CO}_{2}$.

All injections made intravenously, and for guinea pigs, freeze-dried material was used at double the original strength.

\begin{tabular}{|c|c|c|c|c|c|c|}
\hline \multirow[b]{2}{*}{ Sample } & \multirow{2}{*}{$\begin{array}{c}\text { Skin } \\
\text { lesion } \\
0.2 \mathrm{ml} \text {. }\end{array}$} & \multicolumn{3}{|c|}{ Mice* (deaths/no. injected) } & \multicolumn{2}{|c|}{$\begin{array}{c}\text { Guinea pigs* (deaths } \\
\text { no. injected) }\end{array}$} \\
\hline & & $1.5 \mathrm{ml}$. & $1 \mathrm{ml}$. & $0.5 \mathrm{mi}$. & $20 \mathrm{ml}$. & $10 \mathrm{ml}$. \\
\hline
\end{tabular}

Toxin from N.P. strain

\begin{tabular}{|c|c|c|c|c|c|c|}
\hline Alone $\uparrow$ & $7: 38$ & $37 / 46$ & $24 / 41$ & $0 / 10$ & $7 / 9$ & $1 / 3$ \\
\hline With antiserum (i) & Nil & $0 / 5$ & 一 & - & $0 / 2$ & - \\
\hline With antiserum (ii) & Nil & $0 / 5$ & 一 & 一 & - & - \\
\hline \multicolumn{7}{|c|}{ Toxin from Sterne strain } \\
\hline Alonet & $8: 40$ & $24 / 29$ & $57 / 73$ & $11 / 15$ & $9 / 9$ & $9 / 15$ \\
\hline With antiserum (i) & Nil & $0 / 14$ & $0 / 24$ & - & $0 / 5$ & - \\
\hline With antiserum (ii) & Nil & $0 / 10$ & $0 / 10$ & - & - & - \\
\hline
\end{tabular}

* For comparison, the approx. L.D.50 of the anthrax toxin produced in vivo for the mouse and the guinea pig was $0 \cdot 4 \mathrm{ml}$. and $6 \mathrm{ml}$. respectively (Smith et al. 1955).

$\dagger$ When normal horse serum (1/5 volume of toxiefiltrate) was mixed with the toxic filtrates it did not affect either lethality or oedema production.

Specific neutralization by antiserum. The anthrax toxin produced in vivo was specifically neutralized by the serum of horses hyperimmunized against anthrax by using live avirulent Bacillus anthracis spores (Sterne strain) or a non-toxic immunizing antigen produced in vitro by our colleagues Messrs Belton \& Strange (1954). Similarly, the oedema production and lethality of toxic filtrates from cultures of N.P. and Sterne strains of $B$. anthracis were also neutralized by these two types of antiserum (see Table 2.)

Specific precipitation in Ouchterlony plates. Toxin produced in vivo formed a maximum of three precipitation lines when examined in a standard Ouchterlony diffusion system against either of the two sera described above (Stanley \& Smith, personal communication). When compared on the same Ouchterlony plate with the toxin formed in vivo, toxin filtrates from cultures of N.P. and Sterne strains of Bacillus anthracis when concentrated fivefold, formed identical lines against both types of antiserum.

Presence of at least two components forming a synergic mixture. The anthrax toxin produced in vivo could be separated by ultracentrifugation into two 
components-Factor I (deposit) and Factor II (supernatant fluid) (Smith et al., 1956). When injected alone, Factor I had a much lower activity than the original toxin and Factor II (when free from Factor I) was devoid of activity; mixed together, they formed a fully toxic mixture. Our colleague Mr J. L. Stanley ultracentrifuged the toxic culture filtrates from both strains of Bacillus anthracis as described by Smith et al. 1956; after one ultracentrifugation for $16 \mathrm{hr}$. the unwashed deposit (Factor I) was separated from the supernatant fluid (Factor II approx. $8 \mathrm{ml}$.) and dissolved in saline $(3 \mathrm{ml}$.$) . The results of skin tests for synergic action between these two$ factors and with the respective components of the toxin prepared in vivo are shown in Table 3. It is clear that Factors I and II are present in the toxin prepared in vitro.

Table 3. Synergic action of Factors I and II from the toxic filtrates of Bacillus anthracis produced in vitro with each other and with Factors $I$ and II from toxin produced in vivo.

Skin tests for toxin

\begin{tabular}{|c|c|c|c|c|c|}
\hline \multirow{3}{*}{$\begin{array}{l}\text { Strain of Bacillus } \\
\text { anthracis from which } \\
\text { toxic filtrate } \\
\text { prepared }\end{array}$} & \multicolumn{2}{|c|}{ 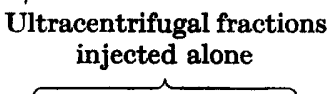 } & & & \\
\hline & \multicolumn{2}{|c|}{$\begin{array}{l}\text { Unwashed supernatant } \\
\text { deposit }\end{array}$} & \multicolumn{3}{|c|}{$\begin{array}{l}\text { Synergic mixtures of } \\
\text { Factor I }(0 \cdot 1 \mathrm{ml} .)+\text { Factor II }(0 \cdot 1 \mathrm{ml} .)\end{array}$} \\
\hline & $\begin{array}{l}\text { Factor I* } \\
(0 \cdot 1 \mathrm{ml} .)\end{array}$ & $\begin{array}{l}\text { Factor II } \\
(0 \cdot 1 \mathrm{ml} .)\end{array}$ & $\begin{array}{l}\text { in vitro I } \\
\text { in vitro II }\end{array}$ & $\begin{array}{l}\text { in vitro I } \\
\text { in vivo II }\end{array}$ & $\begin{array}{l}\text { in vivo } \mathrm{I} \\
\text { in vitro } \mathrm{II}\end{array}$ \\
\hline $\begin{array}{l}\text { In vitro } \\
\text { Strain N.P. } \\
\text { Strain Sterne }\end{array}$ & $\begin{array}{l}8: 24 \\
9: 35\end{array}$ & $\begin{array}{l}\text { Nil } \\
\text { Nil }\end{array}$ & $\begin{array}{l}11: 30 \\
11: 40\end{array}$ & $\begin{aligned} 9: 40 \\
11: 38\end{aligned}$ & $\begin{array}{l}10: 40 \\
10: 35\end{array}$ \\
\hline $\begin{array}{l}\text { In vivoł } \\
\text { Strain N.P. }\end{array}$ & 9:32 & Nil & - & - & - \\
\hline
\end{tabular}

Production of active immunity. Anthrax toxin prepared in vivo will actively immunize guinea pigs against subsequent infection with Bacillus anthracis. A 1/8 or 1/16 dilution of it will protect $c .50 \%$ of the animals in the test for immunizing activity described by Smith \& Gallop (1956). A similar degree of protection in this test was obtained from $1 / 4$ and $1 / 16$ dilutions of toxic filtrates from 4 to $4 \frac{1}{2} \mathrm{hr}$. cultures of the N.P. and Sterne strains, respectively. After $7 \mathrm{hr}$. growth, when the culture filtrates were no longer toxic, they could still immunize although less effectively. Thus, an undiluted filtrate from a late culture of N.P. strain and a 1/2 dilution of a similar filtrate from Sterne strain protected $50 \%$ of the animals. This partial deterioration parallels the behaviour of the in vivo toxin when treated with various chemical reagents; it rapidly loses its toxicity but retains some ability to immunize.

Selective inhibition of toxin synthesis by 2-thiouracil. Tempest \& Smith (1957) showed that in vivo 2-thiouracil interfered with toxin production by Bacillus 
anthracis without significantly affecting its rate of growth. This antimetabolite had a similar action on toxin production by both N.P. and Sterne strains in vitro (Table 4).

Table 4. The effect of 2 thiouracil on toxin synthesis in vitro by Bacillus anthracis

Medium and conditions (optimal inoculum) of incubation as deseribed in Table 1. The number of bacterial chains/ $\mathrm{ml}$. in the growing culture at the different times was not significantly different in control and experimental samples.

\begin{tabular}{|c|c|c|c|c|}
\hline \multirow[b]{2}{*}{ Medium } & \multirow{2}{*}{ Organism } & \multicolumn{3}{|c|}{ Duration of incubation } \\
\hline & & $3 \cdot 5 \mathrm{hr}$ & $\begin{array}{l}4.5 \mathrm{hr} . \\
\text { reaction }\end{array}$ & $6 \mathrm{hr}$. \\
\hline $\begin{array}{l}\text { Control } \\
+ \text { thiouracil }(0 \cdot 1 \%)\end{array}$ & $\begin{array}{l}\text { Sterne } \\
\text { Sterne }\end{array}$ & $\begin{array}{l}6: 37 \\
4: 21\end{array}$ & $\begin{array}{l}7: 42 \\
4: 20\end{array}$ & $\begin{array}{l}\text { Nil } \\
\text { tr }\end{array}$ \\
\hline $\begin{array}{l}\text { Control } \\
\quad+\text { thiouracil }(0 \cdot 1 \%)\end{array}$ & $\begin{array}{l}\text { N.P. } \\
\text { N.P. }\end{array}$ & $\begin{array}{l}6: 32 \\
5: 30\end{array}$ & $\begin{array}{l}6: 35 \\
5: 27\end{array}$ & $\begin{array}{l}\text { Nil } \\
\text { Nil }\end{array}$ \\
\hline
\end{tabular}

The toxin-destroying action of Bacillus anthracis

The effect of bacterial population on toxin production. The results in Table 1 show that toxin production and destruction were related to the number of bacteria in the culture. As soon as a critical amount of growth had occurred (c. 5-10 $\times 10^{7}$ fully developed chains $/ \mathrm{ml}$.), the amount of toxin was maximal and at greater amounts of growth it rapidly disappeared. This was confirmed by the following experiment. When non-toxic, 6-7 hr. cultures of the N.P. or Sterne strains of Bacillus anthracis were centrifuged and the deposited organisms resuspended in the same volume of medium ( 1 vol. tryptic meat broth +9 vol. plasma), no toxin appeared on incubating this relatively high concentration of organisms. On the other hand, toxin was produced when the medium was inoculated with these organisms, when the inoculum was decreased to that normally used for toxin production. Thus, after 2-2.5 hr. of incubation, the toxin gave skin tests of 7-9:35-40. The toxin soon disappeared on further incubation, as the number of bacteria increased.

The toxin-destroying mechanism in organisms from cultures aged $7 \mathrm{hr}$. or more. It seemed likely that organisms found in the older cultures of Bacillus anthracis (N.P. and Sterne strains) could destroy their own toxin. Extracts of organisms from 2.5, 7 and $12 \mathrm{hr}$. cultures and the non-toxic filtrates from 7 and $12 \mathrm{hr}$. cultures were tested for their ability to destroy toxin when incubated with it (see Table 5). In contrast to toxigenic organisms from $2.5 \mathrm{hr}$. cultures, organisms from 7 and $12 \mathrm{hr}$. cultures contained a toxin-destroying mechanism which appeared to be essentially intracellular; at $7 \mathrm{hr}$. it was not present in the culture medium to any appreciable extent, but by $12 \mathrm{hr}$. it was clearly demonstrable, probably due to lysis of some organisms. This apparent change in the organisms between 2.5 and $7 \mathrm{hr}$. was supported by a difference in their infrared spectra; these examinations were made by our colleague Dr K. Norris to whom we are indebted. 
Table 5. The toxin-destroying mechanism in organisms from late samples of cultures of Bacillus anthracis (strains N.P. and Sterne)

\begin{tabular}{|c|c|}
\hline \multicolumn{2}{|c|}{$\begin{array}{l}\text { Skin lesions produced by the } \\
\text { mixtures }(0.4 \mathrm{ml} \text {.) after } 2 \mathrm{hr} \text {. } \\
\text { incubation at } 37^{\circ}\end{array}$} \\
\hline Strain N.P. & Sterne strains \\
\hline $7: 33$ & $7: 32$ \\
\hline $7: 35$ & $7: 33$ \\
\hline $7: 29$ & $7: 31$ \\
\hline $7: 35$ & $6: 31$ \\
\hline Nil & Nil \\
\hline Nil & Nil \\
\hline Nil & Nil \\
\hline Nil & Nil \\
\hline Nil & Nil \\
\hline
\end{tabular}

\section{Mixture}

Sterile toxin* (1 vol.) mixed with 1 vol of:

Saline

Streptomycin solution (2000 u./ml.)

Extract + of organisms from $2.5 \mathrm{hr}$. culturef

Non-toxic filtrate from $7 \mathrm{hr}$. culture

Extract of organisms from $7 \mathrm{hr}$. culture

Non toxic filtrate from $12 \mathrm{hr}$. culture

Extract of organisms from $12 \mathrm{hr}$. culture

(a) Soluble (filtered sterile)

(c) Insoluble

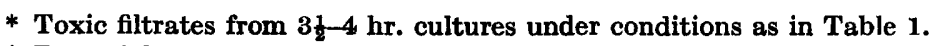

$\dagger$ Bacterial extracts were prepared by shaking in a Mickle shaker with ballotini beads for $\frac{1}{2}-\frac{s}{4} \mathrm{hr}$. No organisms could be cultured from the disintegrates but streptomycin (2000 units per $\mathrm{ml}$.) was added as a precaution since the turbid whole extracts could not be filtered sterile. The concentration of organisms used was equal (on the basis of turbidity) to the concentration in a normal $7 \mathrm{hr}$. culture prepared under the conditions described in Table 1.

$\ddagger$ Conditions of culture as described in Table 1 .

\section{Attempts to increase yields of toxin and prolong its life in cultures}

Quasi-continuous culture. Cultures $(24 \mathrm{ml}$.) of both the N.P. and Sterne strains of Bacillus anthracis were incubated for $4 \mathrm{hr}$. at $37^{\circ}$ under the optimal conditions described in Table 1, i.e. until toxin production was near its peak. Half ( $12 \mathrm{ml}$.) of the culture was then removed for assay and the medium replenished over the next hour by the addition, at $10 \mathrm{~min}$. intervals, of six $2 \mathrm{ml}$. portions of warm medium. After $5 \mathrm{hr}$. of incubation, half $(12 \mathrm{ml}$.) the culture was again removed and the same mode of addition of fresh medium repeated. The whole process was continued until the $8 \mathrm{th} \mathrm{hr}$. of incubation. The bacterial count of all samples of both strains did not depart significantly from $10^{7}$ bacterial chains $/ \mathrm{ml}$. At 4, 5, 6, 7 and $8 \mathrm{hr}$. after the start of incubation the sizes of the skin lesions in the assay for toxin were $6: 37,6: 36,6: 37,6: 44$ and $6: 42$ for the N.P. culture and $7: 42,7: 40,7: 41,7: 46$ and $8: 47$ for the Sterne culture. A comparison of these results with those given in Table 1 shows that when fresh medium was continually added and the bacterial count retained approximately the same by occasional removal of culture, then the high content of toxin which normally disappeared quickly in these cultures was maintained.

Batch culture. Apart from the application of this quasi-continuous culture system, we were not able to maintain peak toxicity or significantly to increase toxin concentration in the standard type of culture where the bacterial population was continually increasing. Attempts in this direction are described below. 
(1) Added nutrients. The following four mixtures of amino acids, purine/ pyrimidines and vitamins produced no significant difference from the control culture when added either alone (at the concentrations given in brackets and at $1 / 10,1 / 50$ and $1 / 500$ of these concentrations) or when mixed together.

A. Glycine $(20 \mathrm{mM})$, DL-alanine $(2 \mathrm{mM})$, DL-valine $(0.4 \mathrm{mM})$, DL-leucine (1 mM), DL-isoleucine (1 mM), DL-proline (1 mM), hydroxyproline (1 mM) DL-serine (2 mM), DL-threonine ( $0 \cdot 4 \mathrm{mM})$, DL-norleucine (1 mM).

B. L-cystine (0.4 mM), DL-methionine (0.4 mM), DL-aspartic acid (1 mM), DL-glutamic acid $(2 \mathrm{mM})$, DL-lysine (1 $\mathrm{mM})$, L-arginine $(1 \mathrm{~mm})$, L-histidine $(0 \cdot 4 \mathrm{mM})$, DL-phenylalanine (1 mM), DL-tyrosine (1 mM), DL-tryptophane $(\mathbf{0} \cdot \mathbf{2} \mathrm{mM})$.

C. Thiamin $(2 \mu \mathrm{M})$, riboflavine $(2 \mu \mathrm{M})$, nicotinamide $(10 \mu \mathrm{M})$, Ca pantothenate $(2 \mu \mathrm{M})$, pyridoxine $(4 \mu \mathrm{M})$ choline chloride $(40 \mu \mathrm{M})$, inositol $(200 \mu \mathrm{M})$, biotin $(2 \mu \mathrm{M})$ pimelic acid $(200 \mu \mathrm{M})$, folic acid (1 $\mu \mathrm{M}) p$-aminobenzoic acid $(10 \mu \mathrm{M})$.

D. Adenine $(100 \mu \mathrm{M})$, guanine $(100 \mu \mathrm{M})$, xanthine $(100 \mu \mathrm{M})$, hypoxanthine $(100 \mu \mathrm{M})$, cytosine $(100 \mu \mathrm{M})$, thymine $(100 \mu \mathrm{M})$, uracil $(100 \mu \mathrm{M})$, glutamine $(1000 \mu \mathrm{M})$, haemin $(80 \mu \mathrm{M})$.

The work of Tempest \& Smith (1957), on the metabolic background to the production of the anthrax toxin in vivo, suggested that addition of coenzyme I $(0.0025 \%)$, coenzyme II $(0.0025 \%)$, uracil $(0 \cdot 1 \%)$, or nicotinamide $(0 \cdot 1 \%)$ might increase toxin production. The addition of nicotinamide and uracil did slightly increase toxin production but this increase was hardly significant.

(2) Constant $\mathrm{pH}$ value. The anthrax toxin is sensitive to changes in $\mathrm{pH}$ value (Smith, et al. 1955). The $\mathrm{pH}$ value of cultures did not fall outside the range 7.4-7.8 during $8 \mathrm{hr}$., and no change in the toxin production and destruction pattern was obtained by adding sodium phosphate to maintain a constant $\mathrm{pH}$ value. The addition of sodium bicarbonate $(0.5$ and $0.1 \%)$ retarded the growth rate somewhat so that toxin was maintained for a slightly longer period.

(3) Oxidizing and reducing substances. Mr J. L. Stanley and Dr H. Smith (personal communication) have found that Factor 1 of the anthrax toxin is sensitive to oxidation and reduction. Addition of cystine (0.1 and $0.01 \%)$, cysteine $(1,0.1$ and $0.01 \%)$ and $\mathrm{KIO}_{3}(0.1 \%)$ with a view to counteracting any oxidizing or reducing action of the organism, produced no significant change from normal. Anaerobic culture resulted in some toxin production of the same pattern as that in normal culture, but possibly slower.

(4) Miscellaneous. Addition of egg-yolk broth (1/5 vol.), arachis oil containing cholesterol $(1 / 5 \mathrm{vol}$.), soya-bean meal containing trypsin inhibitor $(0.5 \%)$, and charcoal $(0 \cdot 1 \%)$ produced no significant change from the normal pattern.

The influence on toxin production of high molecular weight components of serum

The experiments described above gave no clue as to the function of serum and tryptic meat digest medium in producing the right nutritional conditions for toxin production. The effectiveness of the added mixtures of smaller 
molecular nutrilites suggested that it was the larger molecular components of serum which were important in toxin production. The following experiments support this view and also indicate the part played by tryptic meat broth.

When serum alone was used in the standard procedure, toxin production and disappearance was delayed but the maximal content was not significantly lower than when the normal mixture of serum and $10 \%$ tryptic meat digest was used; the function of tryptic meat digest seemed to be to accelerate growth (see top of Table 6). Tryptic meat digest in the standard medium can be replaced by its ultrafiltrate without affecting toxin production or growth (see Table 6), showing that it is the small molecular components which are important. On the other hand, toxin was not produced on a medium of tryptic meat digest or its ultrafiltrate + the ultrafiltrate of serum, although normal growth of the organism occurred. Hence the large molecular weight components of serum appeared to be most important in toxin production.

\section{Production of small amounts of toxin in tryptic meat broth; the influence of serum and other material of high molecular weight}

Only the Sterne strain of Bacillus anthracis regularly produced a small amount of toxin in tryptic meat digest (see Table 6). The N.P. strain produced a similar quantity only in certain batches of tryptic meat digest. A significant increase in toxin production was brought about by the addition of serum $(20 \%, v / v$; see Table 6), but the amount of toxin was not equal to that in the normal mixture of serum and $10 \%(\mathrm{v} / \mathrm{v})$ tryptic meat digest even when the proportion of serum was increased to $50 \%$.

The nature of the high molecular weight components in serum which may be of importance is not clear. Addition of a sample of albumin which had not been specially purified, significantly increased toxin production but a pure sample of albumin and a sample of $\gamma$-globulin did not. The impure sample of albumin was brown and its absorption at $410 \mathrm{~m} \mu$ indicated the presence of haemoglobin. The addition of guinea-pig haemoglobin (not specially purified) increased toxin production but no more than the impure sample of albumin or serum. A fivefold decrease of the haemoglobin concentration did not significantly change the effect. Horse and bovine haemoglobin acted similarly, but haemoglobin could not be replaced by haematin or iron salts.

At no time in this work with media composed mainly of tryptic meat digest, did the concentration of toxin reach that obtained during growth in the conventional mixture of serum with $10 \%(\mathrm{v} / \mathrm{v})$ of tryptic meat broth. The rather low concentrations of toxin obtained were however maintained in the presence of far higher bacterial propulations than in the conventional mixture (see Table 6).

\section{DISCUSSION}

The toxin responsible for death from anthrax has now been produced in vitro from a virulent strain and from an attenuated immunogenic strain of Bacillus anthracis growing in a mixture of serum + tryptic meat digest. The toxin appears identical with that found in vivo, and cultures of the Sterne strain have a 


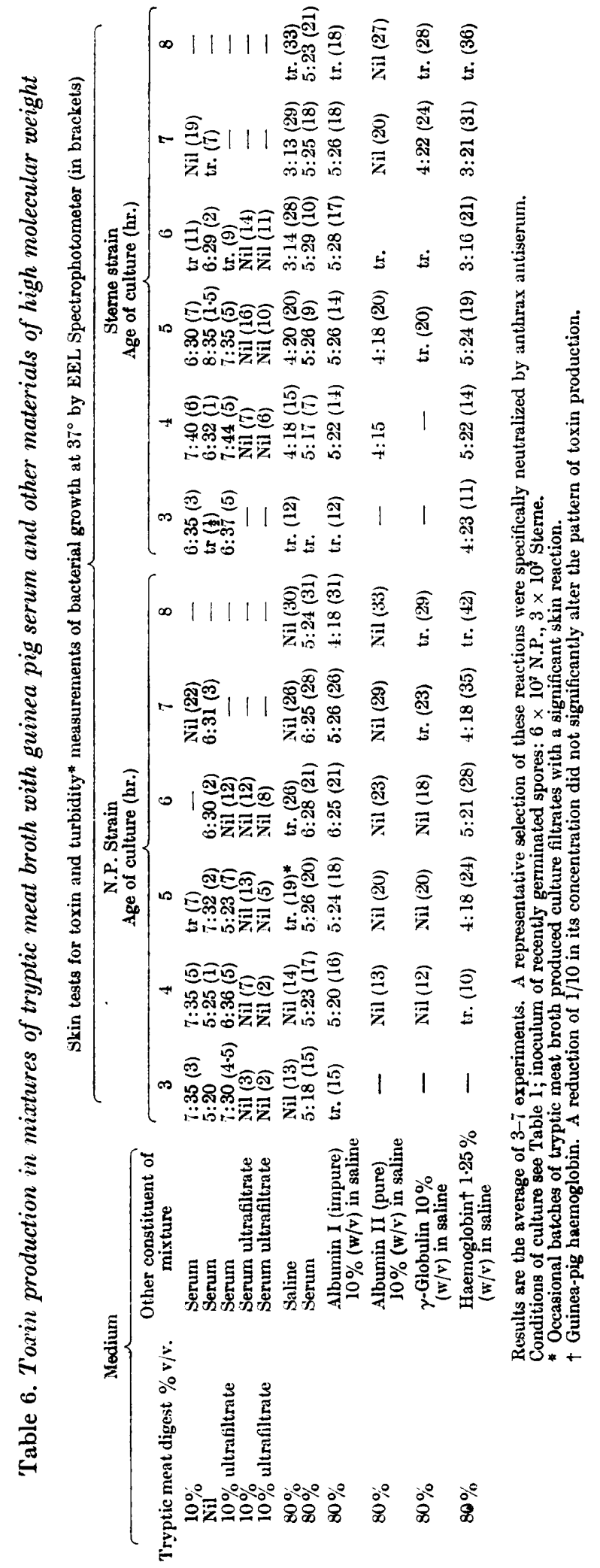


maximum toxin content approximately equal to that produced in vivo. The toxicity of cultures of the virulent strain is $\frac{1}{2}-\frac{1}{4}$ that of toxic plasma.

The early appearance and rapid disappearance of the toxin in artificial culture probably explains the failure of earlier workers to demonstrate it. In culture, Bacillus anthracis organisms change rapidly from toxin producers to toxin destroyers as the result of the production of an intracellular toxindestroying enzyme system. This change occurs when the bacterial population increases beyond a critical concentration. The appearance of this enzyme was prevented by continuous culture in a mixture of serum + tryptic meat digest where the population and nutritional conditions remained more or less constant; under these conditions, the maximum toxin content of the culture was maintained. Hence, the concentration of toxin does appear to cause the change of organisms from toxin producers to destroyers; the change may be due to a nutritional deficiency. Continuous culture is not unlike the conditions which exist in vivo, where any depletion of plasma constituents would be replaced by compensatory mechanisms. One important difference however, is that the bacterial population in vivo increases to $c .1 \times 10^{9} \mathrm{chains} / \mathrm{ml}$. blood, at which concentration complete destruction of the toxin would have occurred in vitro. The compensatory mechanisms of the host appears to be able to supply the correct nutritional environment for a toxigenic bacterial population in excess of that supported by normal serum in artificial culture.

We have been unable to identify in detail the nutritional requirements for toxin production and maintenance. The addition of many nutrilites and the use of various stabilizing procedures have not increased the maximal yield of toxin or prevented its destruction. The large molecular components of serum play an important part in toxin production, and it is interesting to speculate whether these components protect the toxin against the action of the toxindestroying system by acting as competitive enzyme substrates, or whether they provide essential large molecular intermediates for toxin production.

The formation of toxin by the avirulent uncapsulated Sterne strain of Bacillus anthracis fits in with our views on the virulence of this organism and on immunity to anthrax. Virulence is due to at least two factors: the toxin and a capsule which contains polyglutamic acid (Smith, Zwartouw \& HarrisSmith, 1956). Both factors must be present for full virulence; they both act as aggressins and later in the disease the accumulation of toxin proves fatal to the host. The toxin is the complete natural antigen for stimulating active immunity to anthrax. The Sterne organism lacks a capsule and is therefore almost avirulent, but it is a well-known immunogenic strain, either as a spore vaccine or in the form of a filtrate of cultures grown under special conditions (Belton \& Strange, 1954). This strain should therefore produce the toxin in suitable cultures, and this has now been observed. On the other hand, the HM strain is heavily capsulated but since it lacks the capacity to form significant quantities of toxin it is an attenuated strain and non-immunogenic.

Now that the in vitro production of the anthrax toxin in serum has been achieved, it should be possible to succeed also with simpler media. The formation of a trace of toxin in tryptic meat digest, which can be increased by the 
addition of impure serum albumin or haemoglobin is encouraging in this respect. Furthermore, a product closely connected with the anthrax toxin has already been prepared in a chemically defined medium (Wright, Hedberg \& Slein, 1954; Belton \& Strange, 1954). It is a non-toxic protective antigen, which on injection leads to the production of antitoxin capable of neutralizing the anthrax toxin from in vivo (Smith, et al. 1955) or in vitro (see above) sources; it also forms common precipitin lines with the toxin in serological diffusion plate analysis (Mr J. L. Stanley and Dr H. Smith, personal communication) and will, to some extent, replace factors I and II in the tests for oedema production and lethality (Smith et al. 1956).

Our thanks are due to Mr H. Courtney and Mr J. Hayton for excellent technical assistance.

\section{REFERENCES}

Beiton, F. C. \& Strange, R. E. (1954). Studies on a protective antigen produced in vitro from Bacillus anthracis; medium and methods of production. Brit. $J$. exp. Path. 35, 144.

Eurich, F. W. \& Hewletr, R. T. (1930). In A System of Bacteriology, Vol. 5, chap. 10. (Medical Research Council.) London: H.M.S.O.

Keppte, J., Smith, H. \& Harris-Smith, P. W. (1955). The chemical basis of the virulence of Bacillus anthracis. III. The role of the terminal bacteraemia in death of guinea pigs from anthrax. Brit. J. exp. Path. 36, 315.

KInG, H. K. \& SteIn, J. H. (1950). The non-toxicity of Bacillus anthracis cell material. J. gen. Microbiol. 4, 48.

Smith, H. \& Gallop, R. C. (1956). The chemical basis of the virulence of Bacillus anthracis. VI. An extracellular immunising aggressin isolated from exudates of infected guinea pigs. Brit. J. exp. Path. 37, 144.

SMITH, H., KePPIE, J. \& Stanley, J. L. (1955). The chemical basis of the virulence of Bacillus anthracis. V. The specific toxin produced by $B$. anthracis in vivo. Brit. J. exp. Path. 36, 460.

Smith, H., Tempest, D. W., Stanley, J. L., Harris-Smith, P. W. \& Gallop, R. C. (1956). The chemical basis of the virulence of Bacillus anthracis. VII. Two components of the anthrax toxin: their relationship to known immunising antigens. Brit. J. exp. Path. 37, 263.

Smith, H., Zwartouw, H. T. \& Harris-Smith, P. W. (1956). The chemical basis of the virulence of Bacillus anthracis. VIII. Fractionation of the intracellular material of B. anthracis. Brit. J. exp. Path. 37, 361.

Sobernheim, G. (1931). Handbuch der Pathogenen Micro-organismen, Vol. 3, pt 2, p. 1041. Jena: Gustav Fischer, Urban and Schwarzenburg.

Tempest, D. W. \& SмiтH, H. (1957). Studies on the metabolism of Bacillus anthracis growing in the bloodstream of a guinea pig: The effect of metabolite analogues on growth and synthesis of virulence determining factors. J. gen. Microbiol. 17, 739 .

Wright, G. C., Hedberg, M. A. \& Slein, J. B. (1954). Studies on immunity in anthrax. III. Elaboration of protective antigen in a chemically defined, non protein medium. J. Immunol. 72, 263. 